\title{
Evaluation of results of surgical management of lateral tibial condyle fractures using locking compression plate
}

\author{
Govind Kumar Gupta ${ }^{1, *}$, Sudha Rani ${ }^{2}$, Rajkumar ${ }^{3}$ \\ ${ }^{\mathbf{1}}$ Associate Professor, ${ }^{\mathbf{2}, 3}$ Junior Resident, ${ }^{\mathbf{1}, \mathbf{3}}$ Dept. of Orthopaedics, ${ }^{\mathbf{2}}$ Dept. of Anatomy, ${ }^{\mathbf{1 , 3}}$ Rajendra Institute of Medical Sciences \\ (RIMS), Ranchi, Jharkhand, ${ }^{2}$ Mahatma Gandhi Memorial Medical College, Jamshedpur, Jharkhand, India \\ *Corresponding Author: \\ Email: gkgupta1975@yahoo.co.in
}

\begin{abstract}
Introduction: Tibial plateau fractures are the common injuries that may be associated with poor outcomes and a high rate of complications. The problem rise significantly in high energy trauma and severe soft tissue injuries. Locked compression plating system has clear biomechanical advantages and avoids iatrogenic tissue damage when compared with conventional plating. The purpose of surgical management is to restore and preserve normal knee function. It can be accomplished by anatomical restoration of articular surfaces, maintaining mechanical axis, restoring ligamentous stability and preserving a functional pain free range of motion of knee.

Materials and Methods: This is a prospective study of 36 patients with tibial plateau (Schatzker type I, II and III) fractures fixed with lateral locking compression plate over lateral surface of tibia and followed for a minimum period of 6 months and evaluated by using Rasmussen knee score system.

Results: All patients were followed properly but two patients were lost to follow up so only remaining 34 patients were finally evaluated for functional outcome. Mean age of patient was 38.8 years with range of 19 to 70 years. All fractures united by average of 17.5 weeks (range 14-25 weeks) with delayed union observed in 6 cases. Three patients had wound dehisence, three varus deformity, one deep vein thrombosis, four arthritis and five cases of each knee joint pain \& stiffness. According to Rasmussen's scoring system, 52.94\% patients had excellent results, 32.35\% patients had good, $8.22 \%$ fair and $5.88 \%$ poor result.

Conclusions: Locking plates are good option for lateral tibial condyle fractures with minimum complications. Anatomical reduction can be easily maintained with locking plates, which also helps in early mobilization and hence obtaining good functional outcome in tibial condylar fractures.
\end{abstract}

Keywords: Tibial plateau fractures, Schatzker (type I, II and III) classification, Locking compression plate, Rasmussen knee score.

\section{Introduction}

Tibial plateau fractures account for about about $1 \%$ of all fractures in adult and about $8 \%$ in the elderly. ${ }^{1}$ Anatomically medial plateau is cancave and larger while lateral plateau is convex and smaller. Proximal tibia plays a vital role in knee function and stability and is involved in body weight transmission through knee joint and leg. Plateau fractures are associated with variety of soft tissue and bony injuries that can produce permanent disabilities and their treatment is often challenged by severe fracture comminution. Complications of these fractures vary with the degree of trauma energy and include soft tissue injuries requiring coverage procedures, infection, compartment syndrome, peroneal nerve injury, vascular injury, varus collapse, knee stiffness and a consequent secondary osteoarthritis. These fractures may also be associated with cruciate and collateral ligament injuries and meniscal tears. ${ }^{2}$

The majority of tibial plateau fractures are secondary to high speed velocity accidents and fall from heights where fractures results from direct axial compression, usually with a valgus or varus moment and indirect shear forces. Fractures in men occur at a younger age and tend to be the result of high-energy trauma; women have increasing incidence with advancing age particularly the sixth and seventh decades, which indicates these fractures are occurring in osteopenic bone. The severity of injury increases classified by Schatzker classification., ${ }^{3,4}$ Complex fractures include fracture with articular incongruency and depression, displacement of condyles, metaphyseal extension and soft tissue injuries. ${ }^{5}$

The incidence of malunion, non-union and infections are relatively high and may cause significant long term disability. Surgical treatment of proximal tibial fractures should be aimed to restore and preserve normal knee function, which can be achieved by anatomical restoration of articular surface, maintaining mechanical axis, restoring ligamentous stability and preserving a pain free range of motion of knee. ${ }^{4}$

The management of these fractures is still controversial. Conventional non operative modalities like casts, braces or traction have risks of poor clinical outcome and prolonged hospital stay. Operative methods include closed/open reduction and percutaneous cancellous screw fixation, joint reconstruction and stabilization with buttress plate and screws \& external fixator (Ilizarov or tubular type). 
In most open tibial plateau fractures temporary external fixation is done for soft tissue recovery. Once wound heal and infection subsided, delayed definitive surgical treatment can be performed. Each of these methods has its limitations prompting the search for better techniques and implants. ${ }^{6,7}$

Recent advancement in angle stable locking plate technology has allowed for a new approach to this difficult fractures. ${ }^{8}$ Locking compression plate offers potential biomechanical advantage over other methods by, ${ }^{9}$

1. Providing more stable fixation in osteoporotic bones,

2. Providing better unicortical fixation,

3. Better distribution of forces along the axis of bone,

4. Providing more stable fixation by creating a fixed angle construct and angular stability,

5. Better preservation of blood supply to the bone as a locked plate does not causes plate bone compression,

6. Can be easily inserted with minimal soft tissue damage using minimally invasive percutaneous plate osteosynthesis (MIPPO),

7. Reducing risk of loss of intraoperative reduction by locking with screws to the plate,

8. Has ability to manipulate and reduce the small and osteoporotic fragments directly and

9. Allows early mobilization and rehabilitation.

The aim of this study is to evaluate the results of single lateral locking plate fixation in management of lateral tibial plateau fractures.

\section{Materials and Methods}

This study was carried out in the department of orthopaedics, Rajendra Institute of Medical Sciences (RIMS), Ranchi, Jharkhand, for a period of one and half years from August 2015 to January 2017. This is a prospective study of 36 tibial plateau (Schatzker type I, II and III) fractures in patients aged 19-70 years, irrespective of sex, subjected to locking compression plate fixation after obtaining written informed consent. All patients were followed properly but two patients were lost to follow up so only remaining 34 patients were finally evaluated for functional outcome.

\section{Inclusion Criteria:}

1. Age between 19-70 years.

2. Schatzker type I, II and III tibial plateau fractures.

3. Compound grade I (Gustillo-Anderson classification) fracture.

\section{Exclusion Criteria:}

1. Age $<19$ and $>70$ years.

2. Polytrauma patient.

3. Compound grade II \& III(Gustillo-Anderson classification) fractures.

4. Fracture-dislocation of knee injury.
5. Pathological fracture of tibial plateau other than those due to senile osteoporosis.

6. H/O previous osteotomy or fracture over same region.

7. Systemically ill patient.

8. Tibial plateau fractures Schatzker's Type IV, V and VI.

9. Pregnant patients.

On admission the patients were thoroughly assessed clinically. The cause of injury was inquired; vitals parameters were checked; associated head, neck, chest, abdominal injuries were looked for. Any associated injuries were managed appropriately. Immediate resuscitative measures were taken for patients presented with shock. Relevant X-rays were taken when patient's general condition was fit. X-rays were assessed for comminution, involvement of joint, displacement and extension of fracture to the shaft. Computed tomography (CT) scan done in cases where more detailed fracture configuration was needed. Surgery was performed as soon as possible when medical condition, skin condition and limb swelling improved. Fracture was immobilized with an above knee slab if surgery was delayed.

After getting all pre-operative evaluation \& fitness for surgery patient were operated with locking compression plate (LCP). Patients were treated with appropriate antibiotics, analgesics \& anti-inflammatory medications pre \& post operatively.

Operative and Surgical Technique: Spinal/epidural anesthesia was administered. Tourniquet was used in all cases. All operations were done under image intensifier. All patients were operated through anterolateral parapatellar approach using single lateral locked compression plate. With the knee in $30^{\circ}$ flexion an anterolateral curved incision was made starting 3 $\mathrm{cm}$ above the patella proximally and extending distally below the inferior margin of the fracture site (in between Gerdy's tubercle and fibula). Infra meniscal arthrotomy was performed. The articular portion of the tibial plateau was reduced and stabilized as needed with wires or screws. Temporary fixation was done with k-wire when required which also allowed for checking the alignment in coronal and sagittal plane. By applying axial traction reduction was maintained. The appropriate length of locking compression plate was determined by placing a plate along the anterior aspect of leg and adjusting it so that the proximal end of the plate was just below the joint line and the distal end extends at least 4 screw holes beyond the distal limit of tibial fracture. Overall reduction and alignment was maintained by using two parallel cannulated cancellous screws in the plateau and securing a precontoured anatomical locking compression plate to the lateral surface of the tibia. Initially proximal end of plate was secured to condyle and then distal end to the shaft. Bone graft taking from iliac crest was placed 
when required. Tourniquet was released, haemostasis secured, drain placed and wound closed in layers.

Post operatively check x-ray was taken to assess the reduction. The operated limb was kept elevated with both the hip and knee partially flexed. Drain was removed after $48 \mathrm{hr}$ and skin sutures were removed on twelfth post-operative day and patients were discharged. Quadriceps \& hamstring muscle exercises were started on 1st post-op day (depending on fracture fixation \& stability) followed by active \& active assisted range of motion exercises of the knee. Graded weight bearing was allowed depending on X-ray and clinical assessments. The patients were followed up at every 6 weeks for the first 3 months and then at every 3 month interval. In every follow up, the patients were assessed both clinically and radiologically for union and range of motion at knee according to Rasmussen's criteria.

\section{Results}

There were 36 patients with lateral tibial plateau fractures treated with proximal tibial locking compression plate system. Two patients were lost to follow up before six month, therefore 34 patients made the report of this study.

There were $79.41 \%$ (27) men and $20.58 \%$ (7) women with an average age of 38.8 years (range, 1970). There were $61.76 \%$ (21) right-sided and $38.23 \%$ (13) left-sided fractures. $85.29 \%$ (29) patients injured due to road traffic accident, $8.82 \%$ (3) from fall and $5.88 \%$ (2) patients from sports injury. By using the classification system of Schatzker, $14.70 \%$ (5) fractures were type I, $50 \%$ (17) were type II \& $35.29 \%$ (12) were type III. $82.35 \%$ (28) cases had closed and $17.64 \%$ (6) cases had grade 1 open fracture which was treated preoperatively with intravenous antibiotics and antiseptic dressing. The average length of hospitalisation was 21 days with a range of 17 to 35 days. The average number of days from injury to surgery was 11 days (range of 4 to 23 days). The operative time ranged from 65 minutes to 125 minutes with average of 91 minute. None of these cases required a fasciotomy. The mean follow up was 13 months (range 6 to 22 months). 5 patients had concomitant injuries to other systems with head \& chest injury observed in 4 cases, and abdominal injury in 1 case. In 9 cases, other long bone fractures were also present out of which ipsilateral femur and fibula fracture was present in 5 cases. Associated ligamentous injury included 3 cases of medial collateral ligament, 2 cases of anterior cruciate, and 1 case each of posterior cruciate \& lateral collateral ligament. All the ligamentous injuries were managed conservatively by a Brace. Primary bone grafting was done in two cases with depressed fractures, taken from iliac crest.
All fractures united in average 17.5 weeks (range 14-25 weeks). 3 (8.82\%) cases of malunion and 6 $(17.64 \%)$ cases of delayed union were seen. No any case of nonunion was seen in our study. Infection was seen in $7(20.58 \%)$ out of which 4 cases were simple and 3 cases developed wound dehiscence. Simple infections were treated with antibiotics and regular antiseptic dressing. Wound dehiscence was treated with intravenous antibiotics as per culture $\&$ sensitivity report, debridgment and wound coverage when good granulation tissue formed. Average range of motion of knee joint at union was 109.86 (Range $0-130^{\circ}$ ). Stiffness in knee joint (range of motion $<90^{\circ}$ ) was observed in $5(14.70 \%)$ cases. $5(14.70 \%)$ cases had persistent pain at the site of implant, extension lag $\left(5^{\circ}\right.$ 10 ) occurred in $2(5.88 \%)$ cases, deep vein thrombosis in $1(2.94 \%)$ and post traumatic arthritis developed in 4 $(11.76 \%)$ cases. According to Rasmussen's knee score, $18(52.94 \%)$ patients had excellent, $11(32.35 \%)$ had good, $3(8.22 \%)$ had fair while $2(5.88 \%)$ patient had poor clinical outcome.

Table 1: Showing age distribution of patients

\begin{tabular}{|l|c|c|}
\hline $\begin{array}{l}\text { Age group } \\
\text { (In years) }\end{array}$ & No of patient & $\begin{array}{c}\text { Percentage } \\
(\%)\end{array}$ \\
\hline$\leq 30$ & 4 & 11.76 \\
\hline $31-40$ & 13 & 38.23 \\
\hline $41-50$ & 9 & 26.47 \\
\hline $51-60$ & 5 & 14.7 \\
\hline$>7$ & 3 & 8.82 \\
\hline
\end{tabular}

Table 2: Showing mode of injury

\begin{tabular}{|l|c|c|}
\hline $\begin{array}{l}\text { Mode of } \\
\text { injury }\end{array}$ & No of patient & $\begin{array}{c}\text { Percentage } \\
(\mathbf{\%})\end{array}$ \\
\hline RTA & 29 & 85.29 \\
\hline $\begin{array}{l}\text { Fall from } \\
\text { height }\end{array}$ & 3 & 8.82 \\
\hline Sports & 2 & 5.88 \\
\hline
\end{tabular}

Table 3: Showing frequency of complications

\begin{tabular}{|l|c|c|}
\hline Complication & $\begin{array}{c}\text { No of } \\
\text { patient }\end{array}$ & $\begin{array}{c}\text { Percentage } \\
(\%)\end{array}$ \\
\hline Pain & 5 & 14.7 \\
\hline Infection & 7 & 20.58 \\
\hline $\begin{array}{l}\text { Knee } \\
\text { stiffness }\end{array}$ & 5 & 14.7 \\
\hline $\begin{array}{l}\text { Varus } \\
\text { deformity }\end{array}$ & 3 & 8.82 \\
\hline Extensor lag & 2 & 5.88 \\
\hline Arthritis & 4 & 11.76 \\
\hline $\begin{array}{l}\text { Delayed } \\
\text { union }\end{array}$ & 6 & 17.64 \\
\hline $\begin{array}{l}\text { Deep vein } \\
\text { thrombosis }\end{array}$ & 1 & 2.94 \\
\hline
\end{tabular}


Table 4: Showing final outcome (Rasmussen's knee score)

\begin{tabular}{|l|c|c|}
\hline Outcome & No of patient & $\begin{array}{c}\text { Percentage } \\
(\mathbf{\%})\end{array}$ \\
\hline Excellent & 18 & 52.94 \\
\hline Good & 11 & 32.35 \\
\hline Fair & 3 & 8.22 \\
\hline Poor & 2 & 5.88 \\
\hline
\end{tabular}

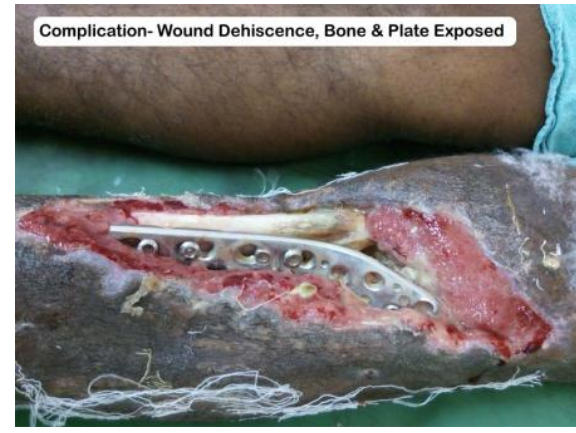

\section{Image 1:}

\section{Discussion}

Proximal tibial fractures have associate soft tissue and bony injuries that can produce permanent disabilities. Fracture comminution, instability, displacement and extensive soft tissue injuries make their management more difficult. The aim of this study was to evaluate the clinical outcome of tibial platue fracture treated with locking compression plate and its complications.

The age of the patients in this study ranged from 19 and 70 (average 38.8) years. Tibial plateau fractures was more commonly seen in the active productive age group (31-50 years) due to high-energy trauma. These fractures were more common in males $(n=27,79.41 \%)$ which could be due to the risk of injury by occupational and ambulant life led by them. Road traffic accident was the most common $(n=29,85.29 \%)$ mode of injury with more $(61.76 \%)$ fractures occurred on right side. These findings are comparable to the studies done by Sharma et $\mathrm{al}^{10}$ and Patil et al. ${ }^{11}$

In our study, average number of days from injury to surgery was 11 days with a range of 4 to 23 days and average operating time was 91 minutes (65-125 minutes). The average length of hospitalisation was 21 days with a range of 17 to 35 days. Mean time between injury and surgery in Sanjay et al ${ }^{12}$ study was 6.65 days (range 1-20 days) and mean duration of hospital stay was 16 days. Delay in surgery in our study might be due to overcrouding of patient in ward, limited hands and resources in our institution.

In our study, 5 patients had concomitant injuries to other systems with head \& chest injury observed in 4 cases, and abdominal injury in 1 case. In 9 cases, other long bone fractures were also present and 7 cases had associated ligamentous injury. All the ligamentous injuries were managed conservatively by a Brace. The patient's function and outcome were good even without addressing these injuries. C V Dasaraiah et al ${ }^{13}$ showed 6 cases of associated ligamentous injury in his study. In Jain D et al series, ${ }^{14} 14$ patients had concomitant injuries to other systems with head injury observed in maximum number of cases and in eight cases, other long bone fractures were also present.

In our study, all fractures united in an average of 17.5 weeks with range of 14 to 25 weeks. Average range of motion of knee joint at union was 109.86 with range of 0 to $130^{\circ}$. In $5(14.70 \%)$ cases knee stiffness was observed. The average time for union of fractures was 19 weeks in Kancherla et $\mathrm{al}^{15}$ series ranging from 16 to 24 weeks and an average of $121^{\circ}$ knee joint range of motion was achieved. In J. Praneeth Kumar Reddy et $\mathrm{al}^{16}$ study, most of these fractures were united by an average of 13.75 weeks ranging from 12 to 20 weeks and average range of motion was 114 degrees with only 1 patient $(3.3 \%)$ had knee flexion of 90 degrees.

In our study, infection occurred in $7(20.58 \%)$ out of which 4 cases were simple and 3 cases developed wound dehiscence. Simple infections were treated with antibiotics and regular antiseptic dressing. Wound dehiscence was treated with intravenous antibiotics as per culture \& sensitivity report, debridgment and wound coverage when good granulation tissue formed. No implant was removed due to infection. Stiffness in knee joint (range of motion $<90^{\circ}$ ) was observed in 5 $(14.70 \%)$ cases. $5(14.70 \%)$ cases had persistent pain at the site of implant, extension lag $\left(5^{\circ}-10^{\circ}\right)$ occurred in $2(5.88 \%)$ cases, deep vein thrombosis in $1(2.94 \%)$ which was treated conservatively, and post traumatic arthritis developed in $4(11.76 \%)$ cases. Malunion was observed in $3(8.82 \%)$ and delayed union in 6 $(17.64 \%)$ cases. No any case of nonunion was seen in our study. Kumar et $\mathrm{al}^{17}$ study, found 4 cases $(8.69 \%)$ of malunion with no nonunion, 2 cases of simple and 4 cases of compound infection. Implant removed in 1 patient due to deep infection. 3 patients of compound fracture developed wound dehiscence. 2 cases $(4.34 \%)$ developed knee stiffness. Sahu Ramji Lal et al ${ }^{18}$ study found complications like knee stiffness 5\% (3/60) cases, malunion 5\% (3/60) cases, delayed union $6.66 \%$ $(4 / 60)$ cases, nonunion $3.33 \%(2 / 60)$ cases, infection $6.66 \%(4 / 60)$ cases, extensor lag $6.66 \%(4 / 60)$ cases and post traumatic arthritis $8.33 \%(5 / 60)$ cases.

According to Rasmussen's knee score, we had final excellent outcome in $18(52.94 \%)$ cases and in 11 $(32.35 \%)$ cases, it was good (overall $85.29 \%$ acceptable results). Only $3(8.22 \%)$ cases had fair while $2(5.88 \%)$ patients had poor outcome. Sanjay et $\mathrm{al}^{12}$ study reported excellent report in $60.0 \%$ (12) cases, good in $30.0 \%$ (6), fair in $5.0 \%$ (1) and poor in $5.0 \%$ (1) cases. Reddy et al ${ }^{19}$ reported an excellent result in $86.7 \%$ of the cases and $13.3 \%$ had good results. Maravi D.S. et $\mathrm{al}^{20}$ observed that $79.54 \%$ of 
patients had good to excellent results while 20.45\% patients had fair results. Our findings are better than Maravi et al report while poorer than Sanjay et al and Reddy et al studies.

\section{Conclusion}

Locking plate has been developed to overcome the limitations associated with conventional plate. These plates improve stable fixation in osteoporotic and metaphyseal bone. The locking plate is a fixed-angle device because angular motion does not occur at the plate screw interface. The use of locked plate allows the surgeon to manage fractures with indirect reduction techniques while providing stable fracture fixation.

There is an increase in the complexity of proximal tibial fractures with increasing road traffic accident. As most of the patients sustained these fractures belong to physically highly active and productive age group, they need optimal treatment to get back to their previous work capacity and avoid long term complications like osteoarthiritis. Though long term follow up is required to complete recovery, still we feel that locking compression plate fixation is very useful in stabilization of these kind of fractures.

\section{References}

1. Koval KJZ, Joseph D. Handbook of fractures. 3rd ed. Philadelphia; Lippincott Williams \&Wilkins;2006.

2. Gavhale S V, Gawhale S K, Gavai P V, Dash K K, Yeragi B S. A prospective study of functional outcome of tibial condylar fractures treated with locking compression plates. Journal of Medical Thesis 2014 May-Aug;2(2):23-27.

3. Schatzker J, Mc Broom R, Bruce D. The tibial plateau fractures. The Toronto experience 1975. Clin Orthop Relat Res.1978;(138):94-104.

4. Rockwood and Green's fractures in adults/ 8th edition/vol 2/section four lower extremity/chap 55/page no 2303-2367.

5. Watson JT: High-energy fractures of the tibial plateau. OrthopClin North Am 1994; 25:723-752.

6. Ilizaov G.A: treatment of fractures -transosseous Osteosynthesis, New York, Sringer, 1990.

7. Tscherne H, Lobenhoffer P. Tibial plateau fractures. Management and expected results. Clin Orthop Relat Res.1993;292:87-100.

8. Musahl V, Tarkin I, Kobbe P, Tzioupis PC, Siska A, Pape H. New trends and techniques in open reduction and internal fixation of fractures of the tibial plateau. J Bone Joint Surg (Br) 2009;91-B:426-33.

9. J. Praneeth Kumar Reddy et al / International Journal of Biomedical and Advance Research 2016;7(3):123-127.

10. Rakesh Sharma, Rajesh Kapila, Brahm Preet Singh, Yadwinder Singh Sohal. Traditional buttress plating v/s MIPO in management of proximal tibial fractures - A clinical study. Pb Journal of Orthopaedics. 2013;14(1):11-6.

11. Patil DG, Ghosh S, Chaudhuri A, Datta S, De C, Sanyal P. Comparative study of fixation of proximal tibial fractures by non-locking buttress versus locking compression plate. Saudi J Sports Med 2015;15:142147.
12. Sanjay K. Gupta, V. P. Pathania, Utkal Gupta, Arjun Gandotra. "Tibial Plateau Fracture Fixed by Locking Compression Plates". Journal of Evolution of Medical and Dental Sciences 2014; Vol. 3, Issue 56, October 27;Page:12711-12716, DOI: $10.14260 /$ jemds/2014/3686.

13. C.V. Dasaraiah et al. Study of Surgical Management of Tibial Plateau Fractures - Functional and radiological evaluation IOSR Journal of Dental and Medical Sciences (IOSR-JDMS) e-ISSN: 2279-0853, p-ISSN: 22790861. Volume 15, Issue 1 Ver. VI (Jan. 2016), PP 18-27.

14. Jain D et al. Results of proximal tibial fractures managed with periarticular locking plates: A series of 34 cases; IJRRMS, Vol-2, No.4;Oct-Dec,2012.

15. Kancherla NR, Hussain KSA, Sreenath M, Chilakamarri VK. Outcome of treatmentof proximal tibial plateau fractures by minimally invasive percutaneous plating osteosynthesis technique. Int J Res Orthop 2016;2:132-7.

16. J. Praneeth Kumar Reddy et al / International Journal of Biomedical and Advance Research 2016; 7(3):123-127.

17. Kumar Sunil et al. Results of single lateral locked plate in complex schatzker type V and VI tibial plateau fractures using minimally invasive fixation techniquesurgical experience in 46 Fractures. IOSR Journal of Dental and Medical Sciences (IOSR-JDMS) Volume 15, Issue 1 Ver. X (Jan. 2016), PP 59-64.

18. Sahu Ramji Lal et al. Comparative study of fixation of tibia plateau fractures by non-locking buttress versus locking compression plate. International Journal of Orthopaedics Traumatology \& Surgical Sciences, December-May 2016, Volume-2 Issue-1, Page 110-118.

19. Reddy JPK, Nazeer BS, Arun HS, Kumar NM. study of surgical management of proximal tibial fractures using locking compression plate. IJBAR. 2016;07(03):123-7.

20. Maravi D.S. et al. Outcome analysis of tibial plateau fractures fixed by single lateral periarticular locking plate. Orthopaedic Journal of M. P. Chapter, Volume 21, No. 2, 2015 page 64-69. 